\title{
Democracia y Lucha armada. MIR y MLN-Tupamaros Osvaldo Torres G.
}

\author{
Pehuén, Santiago, Chile, 2012, 296 págs.

\section{Danny Gonzalo Monsálvez Araneda}

Universidad de Concepción, Concepción, Chile. E-mail: dannymonsalvez@udec.cl

El libro de Osvaldo Torres Gutiérrez, es un trabajo descriptivo, bien documentado y fundamentado en el uso de fuentes y bibliografía general y específica sobre el tema en cuestión, siendo uno de los aspectos más importantes las entrevistas realizadas a dirigentes de las dos organizaciones político revolucionarias que son el centro de su análisis.

En las primeras líneas, el autor deja establecida la pregunta sobre la cual girará su trabajo, por qué dos organizaciones de la izquierda revolucionaria latinoamericana, las más significativas en sus países, que tuvieron similares propósitos y métodos de acción en sus años iniciales y enfrentaron desafíos y experiencias parecidas en sus respectivos contextos políticos, estás hoy en situaciones diametralmente opuestas (p. 11).

Es decir, mientras el otrora MLN-Tupamaros hoy forman parte del Frente Amplio en Uruguay, el MIR se desarticuló a principios de los noventa y lo que actualmente existe son recuerdos y vestigios de un cierto romanticismo de izquierda acotados a determinados espacios de sociabilidad.

Para aproximarse a estos dos movimientos, el autor reflexiona sobre sus estrategias políticas y determinados nudos históricos, entendidos como los procesos fundacionales, las grandes derrotas sufridas y la forma de encarar los procesos de transición hacia la democracia (p. 11).

Importante señalar que el libro no busca formular hipótesis de causa-efecto, sino que analizar y describir dos experiencias y la forma cómo enfrentaron aquellos nudos históricos, particularmente la derrota y posterior transición democrática.

En la introducción, Torres comenta que el año 2005 el médico Tabaré Vásquez asumía la presidencia del Uruguay, terminando con la hegemonía de colorados y nacionales. Uno de los puntos principales del nuevo mandatario, fue la coalición política que lo respaldaba, el Frente Amplio, la unión de socialistas, agrupaciones aliadas y principalmente de dirigentes y ex Tupamaros, quienes se agrupaban en el Movimiento Participación Popular 
(MPP); entre ellos podemos mencionar a José Mujica (p. 15). Paralelamente a aquello, en Chile, algunos grupos y pequeñas orgánicas reunidas en un acto en el estadio Víctor Jara intentaban rearticular el MIR. Citando al autor, Ni la pasividad del acto, la presencia de varios ex dirigentes y militantes históricos, el mensaje del zapatista Subcomandante Marcos, ni la presencia y canciones de Pablo Milanes pudieron crear el piso suficiente para revitalizar un proyecto político que, en realidad, ya no existía al menos desde hacía una década (p. 16).

Por otra parte, en el caso de Uruguay y Chile, el surgimiento de la izquierda revolucionaria, se da en un contexto de inexistencia de dictaduras (como Argentina por ejemplo). Además, la izquierda tradicional de los respectivos países tildaron a estos movimientos de ultra izquierdistas, atrapados en la enfermedad infantil del comunismo. Mientras que desde el exterior, EE. UU. los catalogó de grupos subversivos a los cuales había que enfrentar por medio de una estrategia militar contrainsurgente. Lo cierto es que los sectores sociales que no encontraban representación política para sus intereses dentro del sistema tales como campesinos pobres, los sin tierra, los pobres urbanos sin viviendas, los cesantes, los estudiantes de la enseñanza pública y otros vieron en estas organizaciones una posibilidad de transformación de sus condiciones de vida mediante la acción revolucionaria (p. 19).

En las últimas líneas de la introducción, el autor se interroga por los caminos que siguieron ambas organizaciones durante los primeros años de la década del noventa, mientras el tronco histórico del MIR terminó disolviéndose víctima de múltiples divisiones, en tanto el MLN-Tupamaros escogió adaptarse a la nueva situación uruguaya, insertándose en la institucionalidad democrática. De ahí la importancia de preguntarse, qué hay en las trayectorias políticas de estas organizaciones, qué las lleva a situarse tan diferentes, si tienen un aparente origen común y un objetivo compartido (pp. 26-27).

El capítulo uno tiene como elemento central algunas cuestiones conceptuales, tales como revolución, violencia (armada), programa revolucionario, fuerzas sociales, partido, democracia, historia; es decir, herramientas que resultan operativos para el análisis del tema de estudio.

Importante constatar, -como señala Torres- que la izquierda marxista no ha sido la responsable exclusiva de los discursos revolucionarios ni del uso de la violencia en América Latina. Hay por lo tanto en la región una diversidad de actores, provenientes del mundo liberal (Colombia, Venezuela, Ecuador, entre otros) y nacional-populista (Argentina, Bolivia), que también articularon programas y estrategias que consideraron el desarrollo de la lucha violenta como forma legítima de enfrentarse en sus sociedades virtualmente quebradas por las desigualdades o por las dictaduras oligárquico-militares (pp. 30-31).

Dicho lo anterior, el autor plantea que se hace necesario dejar en 
claro que la violencia en la lucha política de la región no es propiedad de los grupos de izquierda revolucionaria, aquello se enmarca en un discurso anticomunista promovido por los EE. UU.; por lo tanto la violencia política armada no define en sí lo revolucionario o conservador (p. 30).

Sin duda la Revolución Cubana impuso en América Latina la idea de lo que es o debía ser una revolución en el continente (socialista y armada). Este hecho constituyó un referente en la estrategia de lucha revolucionaria de la izquierda. No obstante aquello, el concepto revolución no tiene una única definición política. Citando a Koselleck, el autor señala que revolución es parte de la historicidad de las palabras que cobran distintos significados según la época (p. 37).

El capítulo dos comienza señalando que el MLN-Tupamaros se convirtió en una organización política que abandonó completamente la lucha armada para formar parte del sistema institucional uruguayo, por su parte, el MIR orgánicamente y como continuidad de sus fundadores, no existe hoy, solamente un pequeño grupo ha mantenido una orgánica, que actualmente dirige Mónica Quilodrán (p. 64). No obstante aquello, algunos históricos militantes del MIR han tenido importantes responsabilidades políticas en los otrora gobiernos concertacionistas.

Desde una mirada política, se plantea que tanto Chile como Uruguay constituirían manifestaciones de estabilidad institucional durante la primera mitad del siglo XX, es decir, no ocurrían los quiebres institucionales como los de Argentina, Brasil y, por supuesto, Ecuador, Perú, Bolivia, Venezuela o Centroamérica. Un golpe de Estado en ambos países era impensado (p. 65). Sin embargo, Torres contradice esa mirada, y para aquello da cuenta de los casos de los golpes de Estado en Uruguay de 1933 y Chile en 1924, así como la presencia militar como actores políticos en ambos países. Si bien, estos casos de ruptura institucional, tienden a poner en tela de juicio el discurso de la excepcionalidad de la democracia uruguaya y chilena, no se comparan o tienen la profundidad, violencia represiva o intento refundacional que les imprimieron los golpes cívico-militares de la época de la Guerra Fría y de la doctrina de la Seguridad Nacional (p. 69).

Después de una mirada general al Estado protector de los dos países, el autor cierra este capítulo con una perspectiva de análisis comparativa sobre la izquierda tradicional (p. 75). El texto señala las similitudes de los partidos comunistas de ambos países hacia mediados de siglo XX, especialmente la subordinación a la URSS y su distancia con la Revolución Cubana, específicamente por el papel subsidiario del PC cubano en la revolución. En el caso de los partidos socialistas, compartían su distanciamiento con la URSS, básicamente por el sistema político autoritario y la falta de democracia. Ambos coincidían en una interpretación más latinoamericanista de sus respectivas sociedades (p. 76), de ahí que en los años sesenta adquirirán simpatías por la Revolución Cubana.

El capítulo tres concentra parte importante de la tesis central del 
autor. Va narrando sobre la base de la consulta y prospección de bibliografía especializada, cuadros estadísticos con datos biográficos de los dirigentes más importantes y la historia oral (entrevista con protagonistas) una especie de vidas paralelas de dichas orgánicas; aquello que el autor denomina nudos históricos, momentos políticos en que una organización toma decisiones estratégicas, es decir, que fija una conducta de largo plazo y que, por tanto, tiene efectos durante un periodo importante de su vida política (p. 81).

Tres son los nudos históricos que se hacen presente en el texto, el primer es el proceso fundacional, el segundo la conducta política ante la primera gran derrota de cada organización, basada en la represión sobre ellos y/o el movimiento popular al que pretende representar, y un tercer momento constituye la adaptación a la transición política de las dictaduras a la democracia. Serán los Tupamaros, quienes realicen una mejor lectura del momento histórico que se estaba viviendo, lo cual los llevo -entre otras cosas- a ser parte de la nueva institucionalidad que se estaba construyendo. En contrapartida, el MIR golpeado por la represión y muerte, siguió otro camino que hoy lo tiene circunscrito más bien a un tema testimonial y marginal en la escena política nacional. Al fracaso del golpe de Estado, se sumó no poder capitalizar la adhesión de la población después de más de 17 años de lucha revolucionaria.

El capítulo cuatro es una especie de conclusión que busca dar una mirada de conjunto a los cambios producidos en la sociedad uruguaya y chilena, así como a éstas dos organizaciones políticas revolucionarias durante la década del sesenta. No obstante aquello, el autor señala que En ambos casos se pretende dejar abierta la posibilidad de otras interpretaciones y de incorporar más derivadas de la experiencia que desarrollaron (p. 259).

Para el caso de los Tupamaros, se destaca su concepción de unidad política y social con el pueblo, importante en su crecimiento, sobrevivencia y proceso de reconstrucción. Es decir, no desarrollaron un discurso hacia el movimiento popular que los pusiera en contradicción con las otras fuerzas que allí existían. Asimismo, las discusiones no se ideologizaron entre reformistas y revolucionario. A lo anterior se suma su composición social y generacional del núcleo dirigente y su inclinación por un marxismo más heterodoxo. De esta forma los tupamaros desarrollaron una notable sensibilidad antes los cambios globales y locales, los que no eran negados o enfrentados con voluntarismo -sí se presentaban eran obstáculos a la lucha, sino más bien se adecuaban a ellos para gestar desde los procesos mismos una política más radical (p. 260).

Por otra parte situamos su autonomía financiera y política respecto a la dirigencia de la revolución cubana. Conjuntamente, sus dirigentes no abrazaron la teoría leninista como ideología oficial, por lo tanto, su forma de organización no se refería al clásico centralismo democrático. Tampoco se autodefinieron como vanguardia de la clase obrera, más bien sus defini- 
ciones políticas se hacían considerando también las posiciones de los demás partidos de izquierda, pero no para situarse más a la izquierda, sino para empujarlos tras objetivos que consideraban justos o viables (p. 262).

En el caso del MIR su concepción de unidad social y política del movimiento popular se enmarcó en la idea de asumir la condición de ser el polo revolucionario de la izquierda. Esto los llevó a marcar diferencias y críticas con los comunistas y su influencia reformista en el movimiento obrero. Aquello significó -entre otras cosas- un deterioro en su capacidad de responder con audacia y flexibilidad a las distintas etapas que debió enfrentar, lo que alguna medida está vinculado a la ortodoxia con que se asumió el marxismo-leninismo y la escasa capacidad de construir teoría o nutrirse de ella (265-266). En otras palabras, el MIR, tenía una lectura era muy simple, encuadrada en los parámetros de lo que había definido como su estrategia de guerra popular (p. 266). Por último, se puede agregar su escasa cultura democrática, si bien en su interior se dio una importante discusión, finalmente era Miguel Enríquez quien decidía, integrando las opiniones de los otros.

Desde el punto de vista de los aprendizajes esperados, podemos sintetizarlos en tres, el primero dice relación con el contexto histórico y cultural en el cual surgen estas dos organizaciones: agotamiento de la democracia liberal, legitimar el uso de las armas para resolver con una salida revolucionaria la crisis que experimentan las sociedades de los años sesenta (p. 268-269). En segundo lugar, los respectivos golpes de Estado, y los cambios que se desplegaron con posterioridad, entre ellos el desgaste del socialismo autoritario, el fin de las eras de las revoluciones proletarias y leninistas, abrieron nuevos derroteros respecto a la renovación teórica y política en el seno de la izquierda, así como la concepción de democracia que se debía construir (p. 270). Y en tercer lugar, los Tupamaros lograron derrotar la imagen de extremistas y terroristas que se había construido sobre ellos, por lo tanto tuvieron un triunfo cultural y político; mientras que el MIR, no capitalizó la resistencia desarrollada durante los 17 años de dictadura, tampoco logro reivindicar la legitimidad de su esfuerzo y sacrificio militante, lo cual desembocó en su fragmentación, aislamiento y pérdida de legitimidad ante la ciudadanía.

Por último, destacar el aporte del libro en el sentido del estudio y análisis comparativo que realiza el autor a dos orgánicas que han marcado la historia de la izquierda revolucionaria de América Latina de los últimos 50 años, pero que al día de hoy, se encuentran en situaciones políticas diametralmente opuestas. 